\title{
Aprendizagem organizacional e desenvolvimento de competências: uma síntese a partir da gestão do conhecimento
}

\author{
Marlene Aparecida da Silva Gonçalves Zangiski \\ marlene.zangiski@gmail.com \\ (PPGEPS/ PUCPR)
}

Edson Pinheiro de Lima, Dr. Eng.

e.pinheiro@pucpr.br

(PPGEPS/ PUCPR)

\author{
Sérgio Eduardo Gouvêa da Costa, Dr. Eng. \\ s.gouvea@pucpr.br \\ (PPGEPS/ PUCPR)
}

\begin{abstract}
As organizações estão operando em um ambiente altamente dinâmico e competitivo, tais aspectos caracterizam a “economia do conhecimento”. A aprendizagem organizacional e a formação de competências constituem processos de grande importância para a manutenção e desenvolvimento da competitividade. O objetivo deste artigo é estudar as relações que se estabelecem entre formação e desenvolvimento de competências e aprendizagem organizacional, tendo como contexto as definições estabelecidas pelo desenho ou projeto organizacional. A pesquisa é de natureza teórica e visa construir, a partir da literatura, um quadro conceitual que identifique as relações que se estabelecem entre a formação e desenvolvimento de competências e a aprendizagem organizacional, sendo estas relações mediadas pelo projeto organizacional. O desenvolvimento conceitual do artigo fundamenta-se na articulação de elementos como o conhecimento organizacional, aprendizagem organizacional, competências organizacionais e o projeto organizacional, para formar como produto do artigo uma síntese, na forma de um framework, que represente as relações entre aprendizagem e competências.
\end{abstract}

Palavras-chave: conhecimento organizacional; aprendizagem organizacional; competências organizacionais; projeto organizacional.

Organizations are operating in a highly dynamic and competitive environment; these aspects define the "knowledge economy". Organizational learning and organizational competences development constitute processes of great value for competitiveness maintenance and development. The main objective of this paper is to study the relationships that are being established between competences creation and development and organizational learning, having organizational design specifications as a context. The research project is theoretical in its nature and it intends to construct, based on literature review, a conceptual framework that identifies the relationships, which are established between organizational learning and organizational competences creation and development, taking these relationships as being mediated by organizational design. The paper conceptual development is founded in some key elements articulations as organizational knowledge, organizational learning, organizational competences and organizational design; these concepts are articulated and their synthesis results in a framework that represents the relationships between learning and competence.

Keywords: organizational knowledge; organizational learning; organizational competences; organizational design. 


\section{Introdução}

Um ambiente em que a complexidade e a turbulência das relações socioeconômicas possuem uma dinâmica significativa requer um novo modelo organizacional que desenvolva as qualidades de ser flexível e integrado, ou seja, que desenvolva uma condição favorável à aprendizagem constante e permanente com vistas ao desenvolvimento das competências necessárias.

A aprendizagem organizacional é um processo complexo, permeado e influenciado por um grande número de variáveis, e envolve relações dinâmicas dos indivíduos e da organização com os ambientes internos e externos.

Um dos propósitos do trabalho é analisar a aprendizagem organizacional, identificar os elementos envolvidos e compreender a relação entre o aprendizado e a construção de competências organizacionais. A partir do entendimento do processo de aprendizagem e de formação de competências, pode-se então, teorizar a respeito das implicações destes com o projeto organizacional. Dentre principais desafios que se constituem na análise do processo de aprendizagem, está a conversão do conhecimento tácito em explícito nos níveis individual e organizacional, e a evidenciação de relações causais entre as ações e os resultados de desempenho positivos ou negativos obtidos pela empresa, o que ocorre em função do alto grau de subjetividade das relações causais, intrínsecas ao processo.

A aprendizagem organizacional tem sido discutida por décadas, ganhando maior ênfase e interesse nos últimos dez anos por força de dois aspectos principais: o primeiro foi por atrair a atenção de disciplinas como a Economia e a Sociologia, através da visualização de que a experiência em aprender provém da facilidade para adquirir novos conhecimentos; o segundo aspecto é a percepção, por parte das organizações, da dimensão da importância da aprendizagem organizacional para a competitividade empresarial. (EASTERBY-SMITH; BURGOYNE; ARAUJO, 2001).

A nova economia do conhecimento é fortemente caracterizada pela transição da eficiência individual para a eficiência coletiva, o que determina a competitividade baseada em rede, e não mais em empresas isoladamente. A inserção no ambiente de negócios, cada vez mais complexo, dinâmico e globalizado requer o desenvolvimento de competências essenciais e a formação de parcerias que possibilitem complementar recursos e alcançar a competitividade (FLEURY; FLEURY, 2003). Zarifian (1995) aborda estas mudanças como a transição do "modelo do posto de trabalho" para o "modelo da competência” e expõe as principais razões econômicas para a mudança:

- Mudanças envolvendo todos os níveis da organização, maior impacto na engenharia de concepção, que envolve engenheiros, técnicos e operários;

- Novo contexto econômico dinâmico e crescimento econômico instável, em função da velocidade das mudanças;

- Importância crescente da mudança organizacional como elemento de competitividade.

Fleury e Fleury (2004) abordam emergência da Visão da empresa Baseada em Recursos (VBR) que propõe a utilização dos recursos físicos, financeiros, intangíveis, organizacionais e humanos para criar vantagem competitiva. A diversificação de recursos é um mecanismo organizacional para capturar rendimentos que são tornados viáveis pelos ativos específicos da empresa, uma vez que as firmas diferem em seu modo de operar, o que torna diferente até mesmo à execução de tarefas similares, em função da variação da combinação de recursos (ativos, competências e capacitações específicas), difícil de ser imitada. (FLEURY; FLEURY, 2004). 
As críticas da VBR aos defensores do posicionamento estratégico levaram à criação de um modelo dinâmico, que combina estratégia competitiva, aprendizagem e formação de competências, conforme a Figura 1.

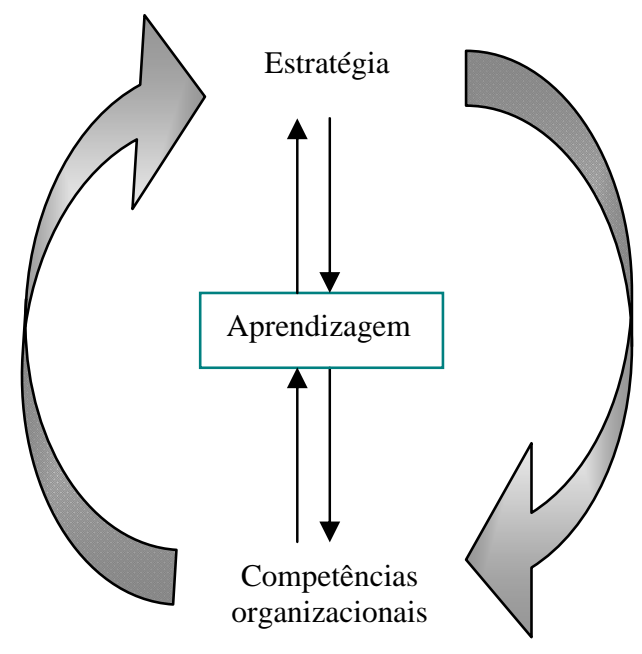

Figura 1 - Ciclo de aprendizagem organizacional (Fonte: FLEURY; FLEURY, 2004)

A criação e o desenvolvimento de competências organizacionais são baseados na aprendizagem, resultante da experiência na implementação de estratégias, através da análise dos resultados contidos no retorno de informações dos ambientes interno e externo da empresa.

O presente trabalho procura organizar estas relações e endereçá-las ao projeto organizacional, de tal maneira que as especificações de projeto favoreçam o desenvolvimento do processo de aprendizagem organizacional. Para tanto, a metodologia utilizada apóia-se na revisão da literatura relacionada ao tema, com o intuito de identificar as variáveis envolvidas e as inter-relações existentes nos processos de aprendizagem organizacional e desenvolvimento de competências, e representá-las em um modeloteórico conceitual.

A estruturação do artigo organiza-se sob a seqüência lógica dos principais elementos inerentes à aprendizagem organizacional, com a definição de conceitos e identificação da importância no contexto da economia do conhecimento. Primeiramente são abordados o conhecimento e a aprendizagem; em seguida, as competências individuais e organizacionais, com aprofundamento no estudo direcionado a estas últimas. Em última instância, o processo de aprendizagem organizacional é definido, bem como as influências sofridas, como barreiras à aprendizagem que exercem influência sobre o ciclo, a geração de conhecimento e construção competências organizacionais. Da compreensão do processo de aprendizagem organizacional e a sua relação com a geração de conhecimento e a formação e desenvolvimento de competências, emerge os elementos ou características que devem ser observados no projeto organizacional.

\section{Revisão de literatura: aprendizagem e competências organizacionais}

As mudanças ocorridas nos anos 60, como o aumento da escala de produção orientada ao comércio internacional, aliadas às transformações recentes provocaram um aumento das incertezas no mercado e estão estabelecendo um novo ambiente competitivo dinâmico e complexo (CHAKRAVARTHY, 1997).

A concepção da estratégia empresarial não pode orientar-se somente pelas questões estruturais (PORTER, 1986) e nem tampouco fundamentar-se na construção de vantagens competitivas genéricas, baseadas na eficiência operacional e na diferenciação (PORTER, 1989). Há que se desenvolver uma visão mais integral da estratégia competitiva, em que as perspectivas de curto, médio e longo prazo possam estar inter-relacionadas (HAMEL; PRAHALAD, 1995). Todas estas características associadas 
à incerteza do mercado e à dinâmica das relações competitivas vêm contribuindo para o resgate de um modelo de negócios baseado em uma visão voltada à gestão estratégica de seus recursos (PENROSE, 1959), particularmente no que se refere à construção de uma estratégia de negócios voltada ao desenvolvimento de recursos, capacitações e competências (WERNERFELT, 1984; WERNERFELT; 1995; BARNEY, 1991). As complementaridades entre as abordagens estruturais, orientadas a formação das vantagens competitivas sustentadas pela diferenciação e eficiência operacional, e as fundamentadas no desenvolvimento de recursos, capacitações e competências, vêm sendo exploradas nos novos modelos de negócio e de estratégia competitiva (FLEURY; FLEURY, 2004; VOLBERDA, 1997; TEECE; PISANO; SHUEN, 1997; TEECE; PISANO, 1994; STALK; EVANS; SHULMAN, 1992) de tal maneira a desenvolver uma visão integral e integrativa a respeito da estratégia competitiva.

Neste contexto, cada novo estágio evolutivo do mercado traz uma exigência complementar a anterior, ou seja, desenvolve-se uma trajetória cumulativa de formação de competências. Tais competências representam uma síntese entre as necessidades de mercado, consolidadas no padrão de concorrência (KUPFER, 1991), e a formação e desenvolvimento da visão (SANCHEZ; HEENE, 1997a; CHIEZA; MANZINI, 1997; SANCHEZ; HEENE; THOMAS, 1996). A economia do conhecimento desenvolvese neste contexto em que a base de conhecimento das organizações é intensamente mobilizada e ampliada para a formação de novas capacitações e competências (SANCHEZ, 1997; SAVAGE, 1996). O processo organizacional que fundamenta tal comportamento é o de aprendizagem organizacional, ou seja, o produto ou resultado deste processo é a formação de competências, sendo que estas representam a mobilização dos recursos e capacitações organizacionais, particularmente o recurso 'conhecimento' (WHITEHILL, 1997; SANCHEZ; HEENE, 1997b). Torna-se, portanto, necessária a definição de conceitos como 'conhecimento organizacional' e 'aprendizagem organizacional', para que se possa estudar a formação e desenvolvimento de competências e a sua relação com o projeto organizacional.

\subsection{Fundamentos da aprendizagem organizacional}

A aprendizagem organizacional é um processo de natureza comportamental que se estabelece tanto no subsistema técnico, como também no subsistema social (GARVIN, 1998). Deve-se, no entanto, destacar que o 'produto' deste processo representa a inter-relação entre estes dois subsistemas. Na perspectiva da visão técnica, a aprendizagem organizacional refere-se ao processamento eficaz, interpretação e resposta de informações internas e externas à organização, e a discussão principal está relacionada à quais formas de mudança estão associadas à aprendizagem. Complementarmente, a perspectiva social trata de estudar como as pessoas atribuem significado às suas experiências de trabalho, sendo que estas experiências podem ser de fontes explícitas, como as informações financeiras, ou tácitas, pela percepção ou "sensibilidade”; logo, segundo esta visão a aprendizagem origina-se das relações sociais.

Para Fernandes (1998), na compreensão da aprendizagem organizacional deve-se explorar a forma pela qual as empresas constroem, incrementam e organizam conhecimento e rotinas, e as suas relações com resultados e processos que ocorrem no interior das organizações. Tal estudo deve incorporar o seguinte conjunto de premissas:

- A aprendizagem geralmente tem conseqüências positivas, mesmo quando os resultados são negativos, pois o produto deste processo está na compreensão das relações de causa-efeito;

- Mesmo que o aprendizado centre-se no indivíduo, as empresas também podem aprender, pois pode-se estabelecer uma representação social ao processo de aprendizagem organizacional;

- A aprendizagem ocorre através de todas as atividades da empresa, em diferentes processos e em diferentes níveis.

Empresas que desenvolvem estratégias para gerir o conhecimento são definidas como "organizações que aprendem”, e caracterizam-se pelo estímulo ao aprendizado individual das pessoas, pela disseminação da cultura de aprendizagem entre clientes e fornecedores, pelo desenvolvimento de uma 
estratégia centrada no desenvolvimento de recursos humanos e pela busca da transformação contínua (SENGE, 1990).

A efetividade da aprendizagem organizacional e da geração de conhecimento é determinante para a formação das competências organizacionais. Argyris e Schön (1996) propõem a existência de dois tipos de aprendizagem, a tipo single-loop e a do tipo double-loop. A aprendizagem do tipo single-loop busca a manutenção do conhecimento, é uma aprendizagem instrumental, que muda estratégias de ação ou suposições acerca desta estratégia, de tal forma a deixar que os valores de uma teoria de ação permaneçam inalterados, ou seja, detecta e corrige o erro, mas não altera o modelo vigente. Este tipo de aprendizagem é mediado pela investigação organizacional, busca detectar erros nas estratégias organizacionais e suas suposições, que podem ser modificadas para sustentar o desempenho organizacional dentro de uma escala de valores e normas da organização. As normas e valores continuam imutáveis neste tipo de aprendizagem, pode transformar-se em uma rotina que prejudica a adaptabilidade e a flexibilidade. Há dificuldades em aprender focando somente na reflexão sobre o problema, ou seja, não revendo a sua especificação.

A aprendizagem do tipo double-loop tem por princípio questionar o que se aprende e revisar princípios, e é indicada para mudanças na cultura organizacional, uma vez que resulta em uma mudança de valores da teoria em uso, bem como da estratégia e suas suposições. Este tipo de aprendizagem foca na correção do erro depois da revisão dos valores inerentes ao modelo, e é o mais adequado para transformações. Refere-se a dois laços de realimentação (double-loop feedback) que se conectam aos efeitos observados da ação junto com a estratégia e os valores que sustentam tal estratégia, assim, as estratégias e suas suposições podem ser alteradas em função de uma mudança de valores. (ARGYRIS; SCHÖN, 1996). A Figura 2 resume as características dos tipos de aprendizagem propostos por Argyris e Schön (1996).

\begin{tabular}{|c|c|}
\hline Single-Loop & Double-Loop \\
\hline $\begin{array}{cl}\text { Valores preponderantes dos adeptos: } \\
\text { - } & \text { Ter controle unilateral das situações } \\
\text { - } & \text { Esforçar-se para ganhar e para não perder } \\
\text { - } & \text { Suprimir os sentimentos negativos próprios e } \\
& \text { alheios } \\
\text { • } & \text { Ser o mais racional possível } \\
\text { Ações: } & \\
\text { - } & \text { Defender sua posição } \\
\text { - } & \text { Avaliar os pensamentos e as ações dos outros (e } \\
\text { - } & \text { seus pensamentos e ações) } \\
\text { Resultados de aprendizado: } \\
\text { - } \quad \text { Os resultados são limitados ou inibidos } \\
\text { - } \quad \text { Há conseqüências que encorajam os mal- } \\
\text { - } \quad \text { entendidos } \\
\quad \text { Surgem processos de erro auto-alimentáveis }\end{array}$ & 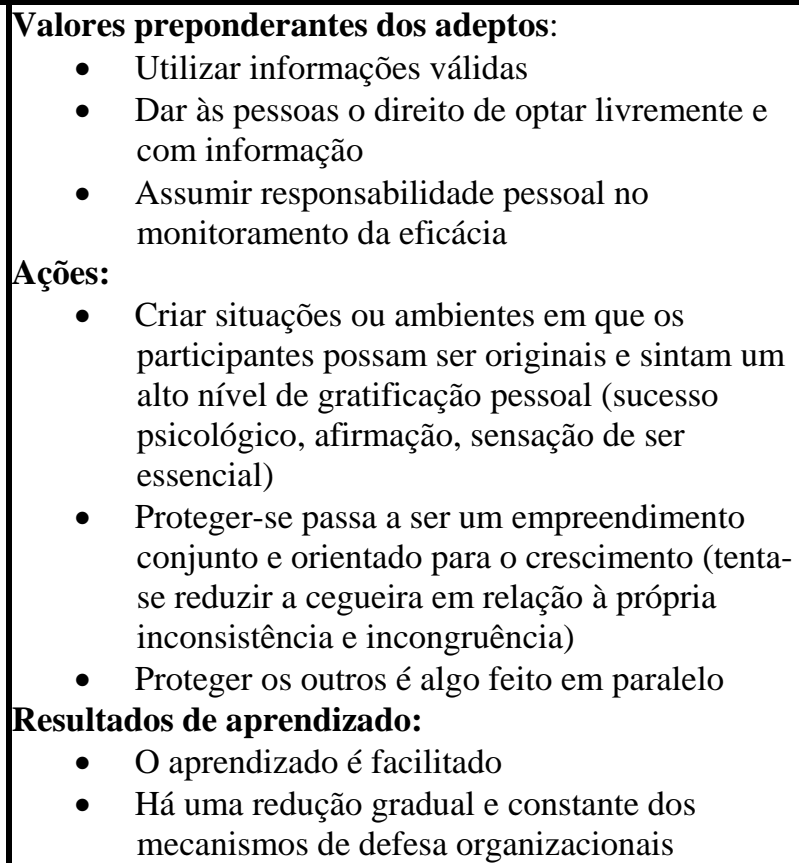 \\
\hline
\end{tabular}

Figura 2 - Tipos de aprendizagem e suas características (Fonte: ARGYRIS; SCHÖN, 1996)

Para Argyris e Schön (1996) a mudança do modelo de aprendizagem Single-Loop - Modelo 1 - para Double-Loop - Modelo 2 - requer muita prática e é guiado por seis regras:

1. É necessário que as pessoas tomem consciência de seus Modelos 1;

2. Deve-se ajudá-las a perceber a inconsciência habilidosa e a incompetência habilidosa;

3. Aumentar a conscientização sobre as conseqüências para a organização; 
4. Deixar que as pessoas relacionem esse tipo de conhecimento às decisões empresariais do diaa-dia;

5. Praticar e fazer com que os outros pratiquem bastante, focalizando problemas que as pessoas consideram importantes;

6. Não passar ao próximo nível hierárquico de uma organização enquanto não comprovar que os altos escalões começam a comportar-se em consonância com o Modelo 2;

7. A aprendizagem passa a ser um processo central para que se desenvolva um processo maior de mudança organizacional e também para que se possam desenvolver as competências necessárias para tal mudança.

\subsection{Conhecimento organizacional}

O conhecimento organizacional pode ser definido como um conjunto de "crenças" associadas às relações de causa-efeito, tendo como nível de representação o sistema organizacional (SANCHEZ e HEENE, 1997b). Estas “crenças” são de caráter coletivo e são representadas através de estruturas de conhecimento organizacional (PEREIRA; PINHEIRO DE LIMA; RODRIGUES, 1999).

Para Nonaka (1991) e Fleury e Fleury (2004), o conhecimento pode assumir representações tangíveis e intangíveis que caracterizam respectivamente o conhecimento explícito e tácito. Nonaka (1991) estabelece que o conhecimento tácito (capital humano) está contido nas estruturas cognitivas dos colaboradores da organização, e o conhecimento explícito (capital estrutural) está representado nas bases de dados, nos arquivos de clientes, softwares, manuais, etc. O conhecimento explícito pode ser explicado e codificado, e é resultante de repetições e rotinas. O conhecimento tácito engloba o ajustamento de crenças e normas, se apóia na memória organizacional e resulta em novos quadros de referência, novas habilidades, e até mesmo à substituição de conhecimentos anteriores que perderam o valor para a organização.

O capital intelectual das empresas é formado por estes dois tipos de conhecimento e seu valor é determinado por fatores como: compatibilidade de idéias com os valores da companhia; alinhamento com a aspiração da alta gerência e os objetivos estratégicos; e o seu potencial para construção de uma rede de conhecimento organizacional (NONAKA, 1991).

De acordo com Sellen (2000), o conhecimento organizacional deve ser tratado como um recurso organizacional que é articulado ou mobilizado dentro dos processos de aprendizagem organizacional. O valor estratégico deste recurso pode ser avaliado através da formação e desenvolvimento de competências, visto que estas mantêm uma relação direta com os processos organizacionais e estes, por sua vez, são responsáveis pela realização da estratégia empresarial ou de negócios. Na visão baseada em recursos, o conhecimento é tido como um recurso fundamental a ser mobilizado em combinação com os demais recursos da organização.

\subsection{Competências}

Pela definição do senso comum, competência é a qualificação para realizar algo, mas no mundo dos negócios este conceito é bem mais abrangente e profundo e aborda características pessoais, como conhecimento, habilidades e atitudes; como também o desempenho associado às atividades. Entre os profissionais de $\mathrm{RH}$, a definição mais comumente utilizada é conjunto de conhecimentos, habilidades e atitudes que afetam a maior parte do trabalho e que se relacionam com o desempenho no trabalho; a competência pode ser mensurada, quando comparada com padrões estabelecidos e desenvolvidos por meio de treinamentos (FLEURY; FLEURY, 2001).

Segundo Fleury e Fleury (2004), no contexto organizacional, a competência é vista da perspectiva individual como uma característica pessoal que possibilita desempenho superior na realização das tarefas, ou frente a situações adversas, o que diferencia, fundamentalmente, competência de aptidão, que é um talento natural aprimorado de habilidades. 
Para Fleury e Fleury (2004), o conceito de competência só revela seu poder heurístico quando aprendido no contexto de transformações do mundo do trabalho das empresas ou sociedades. A abrangência do conceito de competência instiga a investigação e o aprendizado constante, sem necessariamente invalidar elementos que fazem parte do conceito pré-existente.

A comunicação eficiente é fundamental para que o conhecimento seja compartilhado e gere competências. Para estes autores, a competência sempre está ligada a comportamentos, conforme é apresentado na Figura 3.

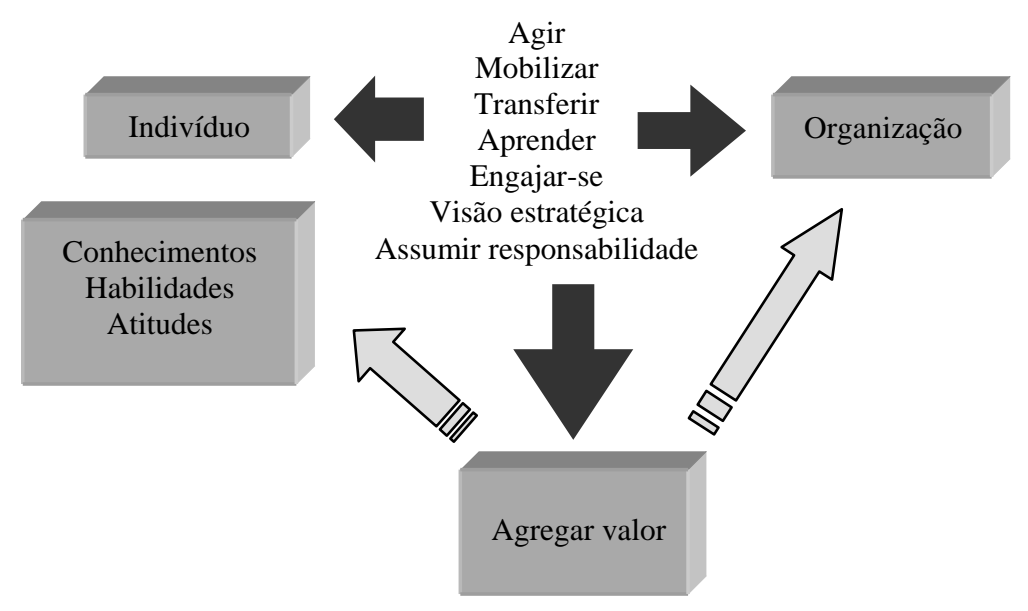

Figura 3 - Comportamentos ligados a competências (Fonte: FLEURY; FLEURY, 2004, p. 30)

Fleury e Fleury (2004) definem competência como um saber agir responsável e reconhecido, que implica mobilizar, integrar, transferir conhecimentos, recursos, habilidades, que agreguem valor econômico à organização e valor social ao indivíduo.

Para Zarifian (2001), o valor econômico agregado pela competência engloba, além da dimensão clássica baseada em aumento de produtividade e redução custos, a dimensão qualitativa influenciadora das escolhas dos clientes, que os economistas clássicos chamam de 'valor de uso'.

Desenvolvido o conceito no nível individual, particularmente no contexto da organização do trabalho, pode-se tratar da definição do conceito de competência no nível organizacional.

\subsubsection{Competências organizacionais}

Decorre da abordagem baseada em recursos na sua aplicação para a gestão estratégica do conhecimento, a definição para competências organizacionais. Competência organizacional é a "habilidade" de coordenar a distribuição dos recursos e capacitações da organização em uma direção estabelecida, para se atingir os seus objetivos (SANCHEZ; HEENE, 1997b).

Na visão Prahalad e Hamel (1990), a competência define a lógica para mobilização de recursos, logo, os resultados de desempenho são conseqüências do nível de competência. As competências não são consumidas ou extintas quando aplicadas, mas desenvolvem-se e crescem através da aprendizagem. As competências organizacionais sustentam as potencialidades de acesso e a permanência nos mais variados mercados.

Mills et al (2002) classificam as competências organizacionais em categorias, destacando as suas características dinâmicas. A Figura 4 resume tal classificação.

\begin{tabular}{ll}
\hline Categorias de competência & Descrição \\
\hline Competências essenciais & $\begin{array}{l}\text { Competências e atividades mais elevadas, no nível corporativo, são chaves } \\
\text { para a sobrevivência das empresas e centrais para a estratégia. }\end{array}$ \\
\hline
\end{tabular}




\begin{tabular}{ll}
\hline Competências distintivas & $\begin{array}{l}\text { Competências e atividades que os clientes reconhecem como diferenciadores } \\
\text { de seus concorrentes e que provêem vantagens competitivas. }\end{array}$ \\
\hline $\begin{array}{l}\text { Competências organizacionais } \\
\text { ou das unidades de negócios }\end{array}$ & $\begin{array}{l}\text { Competências e atividades chave esperadas de cada unidade de negócios da } \\
\text { empresa, geralmente em pequeno número, de três a seis. }\end{array}$ \\
\hline Competências de suporte & Atividade valiosa para apoiar um leque de outras atividades. \\
\hline Capacitações dinâmicas & $\begin{array}{l}\text { Capacidade da empresa em adaptar suas competências com o tempo. É } \\
\text { diretamente relacionada aos recursos importantes para mudança. }\end{array}$ \\
\hline
\end{tabular}

Figura 4 - Categorias de competências (Fonte: MILLS et al, 2002, p. 13)

Na maioria das vezes, o uso das palavras capacitações e competências ocorre de forma intercambiável, mas a abordagem das capacitações dinâmicas é uma exceção. As capacitações dinâmicas são determinantes para a adaptação das competências e atividades ao longo do tempo, e quando a organização desenvolve suas capacitações dinâmicas, expressa ter consciência da necessidade de adaptar as competências continuamente (MILLS, 2002).

No conjunto de competências organizacionais, as competências essenciais, conforme sua própria designação, são enfatizadas como fundamentais, e caracterizam-se como recursos intangíveis, difíceis de serem imitados pelos concorrentes, e essenciais para o provimento de recursos e serviços diferenciados para o mercado e os clientes (FERNANDES, 2004).

Fleury e Fleury (2003) mencionam que as competências essenciais podem estar em qualquer função administrativa, e seu desenvolvimento no longo prazo requer um processo sistemático de aprendizagem e inovação organizacional. O modelo de estratégia e formação de competências pressupõe que toda empresa possui competências em três funções básicas: operações (produção e logística); desenvolvimento de produto; e comercialização (vendas e marketing). A importância de uma determinada função varia conforme o produto ou o mercado de atuação da empresa, e quando uma função se torna mais relevante para a realização da estratégia competitiva e o desempenho da empresa, as demais se tornam funções de apoio. Assim, o desempenho de uma estratégia e a maximização da competitividade de uma determinada empresa estão relacionados ao alinhamento correto entre as competências essenciais e estratégia competitiva (FLEURY, 2003).

Fleury e Fleury (2003) classificam a estratégia competitiva em três categorias:

- Excelência operacional: o determinante de competitividade é a relação qualidade/preço e o fundamento básico da estratégia é a otimização desta relação, as competências essenciais localizam-se na função crítica de operações;

- Inovação em produto: inovação constante de produtos/serviços é o elemento fundamental da competição e a função crítica é pesquisa, desenvolvimento e engenharia (P\&D\&E);

- Orientação para o cliente: neste modelo as ações estratégicas são voltadas para as necessidades de clientes específicos, e a prioridade é o desenvolvimento de conhecimento sobre cada cliente e seu negócio. Um bom exemplo são os fabricantes de embalagens que desenvolvem soluções específicas que maximizam o valor do produto do seu cliente.

Para Hamel e Prahalad (1995) muitos são os riscos potenciais para as empresas que não visualizam suas competências essenciais:

a. A não visualização das oportunidades de mercado possibilitadas por uma competência detida pela empresa limita as oportunidades de crescimento.

b. Mesmo com a identificação de novas oportunidades, existem vários elementos que dificultam a colocação de pessoas que detenham as competências necessárias em contato com a nova área de oportunidades, em outras palavras, "não existem mecanismos claros para alinhar os melhores talentos às melhores oportunidades", o que resulta no não aproveitamento do potencial dos recursos humanos e oportunidades de crescimento.

c. Divisão da empresa em muitas unidades menores, fazendo com que as competências fiquem divididas e percam força, porque as fronteiras criadas podem dificultar a transferência de informações e o aprendizado. 
d. Ausência de perspectiva das competências essenciais, fazendo com que a empresa valorize mais o "aluguel” das competências dos concorrentes ao invés de criá-las, tentando alcançar a competitividade de forma perigosa no que diz respeito à sustentabilidade no longo prazo.

e. É necessário desenvolver competências no presente para crescer no futuro, logo, direcionar-se sempre para os produtos finais impossibilita os investimentos adequados em competências essenciais capazes de alavancar um crescimento futuro.

f. A empresa que não compreende as competências essenciais básicas do setor no qual está inserida pode ser surpreendida por uma concorrente que detém competências que foram desenvolvidas para outros mercados finais, mas que podem ser usadas como fator de competitividade em novos mercados.

g. Quando as empresas decidem sair de um determinado negócio, podem, sem perceber, abrir mão de competências essenciais importantes, que se vão junto com este negócio. É necessária a concepção da dimensão do "mau negócio” e das competências essenciais relacionadas a este negócio.

h. Segundo Boog (1991), para que a organização saiba que competência desenvolver e, portanto, se organizar adequadamente, é necessário o conhecimento das mudanças que ocorrem no ambiente no qual ela está inserida, o que faz a interação entre empresa e ambiente um importante campo de análise. A análise e atenção às mudanças no contexto de competição fornecem subsídios que servem de base para a definição de que competências a empresa precisa desenvolver para atender aos requisitos do mercado. A Figura 5 representa 0 intercâmbio de informações entre a empresa e o mercado.

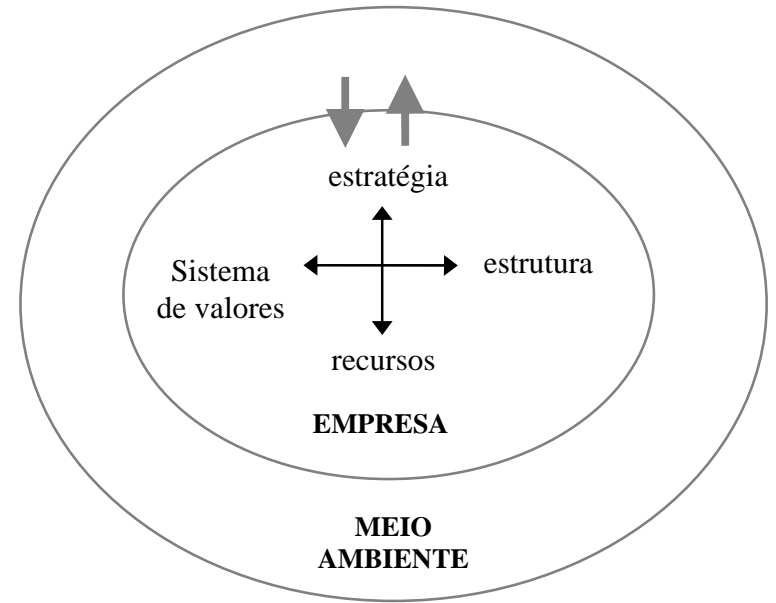

Figura 5 - Interação com o ambiente de mercado (Fonte: BOOG, 1991, p. 16)

Hamel e Prahalad (1995) consideram que são necessárias algumas atividades fundamentais para a administração das competências essenciais:

a. Identificar as competências essenciais existentes:

A administração das competências essenciais requer clareza na identificação destas competências. Muitas empresas possuem dificuldades em estabelecer relações entre as habilidades e a competitividade de produtos e serviços finais, tendo em vista que durante este processo, cada participante tenta incluir entre as essenciais as atividades por ele gerenciadas. Entre as várias armadilhas nas quais as empresas podem cair durante o processo de identificação de competências, duas são mais freqüentes: a primeira é restringir esta tarefa ao departamento técnico, no entanto, competências essenciais dizem respeito a todo o processo administrativo; a segunda é a definição equivocada de ativos e infra-estrutura como competências essenciais. Há também uma grande dificuldade em perceber a ligação entre competência e benefício, ou que competência permite gerar o valor percebido pelo cliente. É importante que funcionários de várias áreas da empresa participem do processo de identificação de competências essenciais, a diversidade de visões favorece uma definição mais precisa e apurada. Identificar competências é um processo amplo e profundo, e traz a tona divergências de idéias, surgimento de idéias, visão de 
oportunidades potenciais antes não percebidas, e o objetivo é desenvolver uma visão ampla e detalhada, e não uma relação baseada em checklist.

b. Definir uma agenda de aquisição de competências essenciais:

A agenda de desenvolvimento de competências para as empresas é determinada pela sua arquitetura estratégica. A Figura 6 ilustra tal arquitetura.

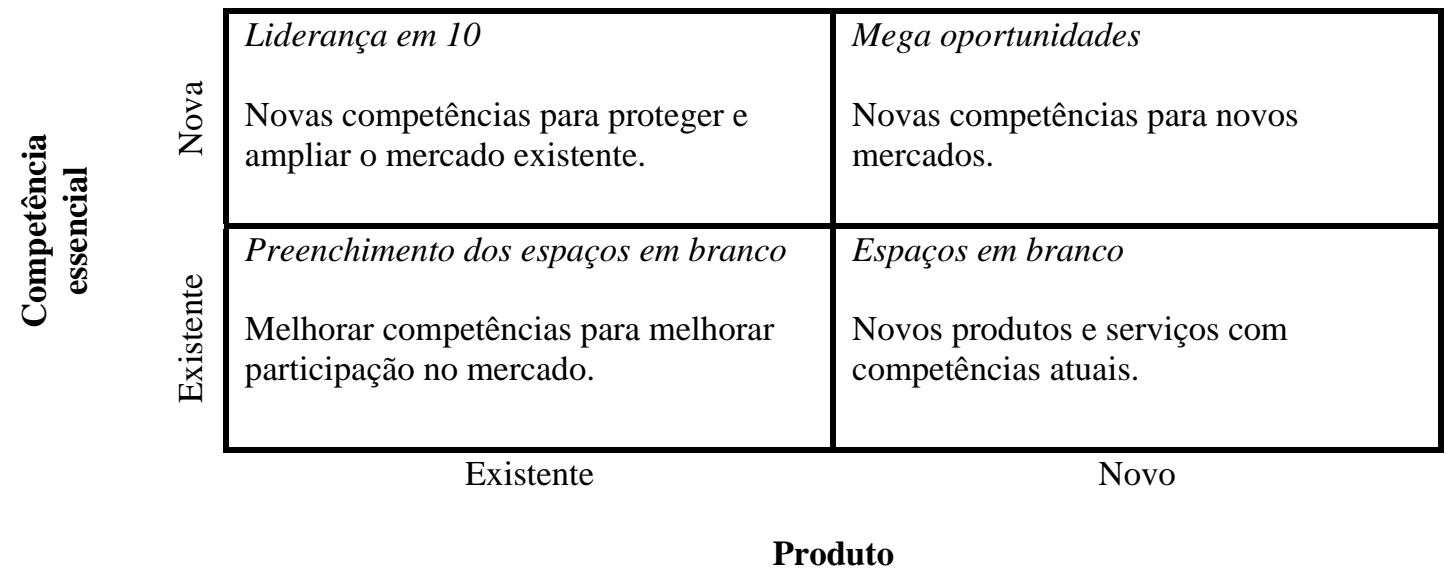

Figura 6 - Definição da agenda de competências essenciais (Fonte: HAMEL; PRAHALAD, 1995, p. 264)

c. Desenvolver as competências essenciais:

O desenvolvimento de competências requer consenso sobre as competências que serão desenvolvidas. Também demanda uma estabilidade das equipes gerenciais envolvidas com tal desenvolvimento. A rotatividade de pessoal entre os líderes do projeto pode comprometer seus objetivos, em função das interrupções, em um processo de aprendizado lento, que requer persistência e se desenvolve de maneira cumulativa.

d. Distribuir as competências essenciais

Muitas empresas têm um estoque grande de competências essenciais, mas que estão alocadas em áreas não adequadas, o que resulta em uma velocidade de utilização de competências quase igual a zero.

A distribuição possibilita o uso das competências existentes de forma mais eficaz e otimizada, em outras palavras, alocar os indivíduos onde as competências detidas por eles tenham maior velocidade de aplicação. Comparando a alocação de capital à alocação de talentos que constituem as competências essenciais: a alocação bem sucedida de capital é vista como uma das formas de agregar valor à organização; com a alocação de competências deveria ser similar, pois competências adequadamente alocadas agregam valor para a organização, e como na alocação de capital, justificam suas despesas.

As diferenças entre o valor de mercado e o valor contábil dos ativos não é uma disparidade que refere-se à reputação da empresa, mas sim ao valor agregado pelas competências essenciais que não são contabilizadas. São relações do tipo 2:1, 4:1, 10:1, onde o numerador expressa a crença dos investidores em relação à singularidade e competitividade das competências detidas pela empresa.

A alocação inadequada de talentos desperdiça recursos duplamente, pois investe capital equivocadamente no indivíduo que não detém as competências requeridas, e desperdiça recursos financeiros que poderiam ser ganhos com o mesmo investimento no talento adequado àquela área da organização.

Um desequilíbrio em termos de distribuição de poder entre as áreas financeira e de recursos humanos pode ser um obstáculo ao desenvolvimento de competências.

\section{e. Proteger e defender a liderança das competências essenciais:}


A proteção das competências essenciais requer vigilância contínua da alta gerência, muito embora a maioria dos gerentes possa identificar as medidas que levaram ao bom desempenho, poucos conseguem definir claramente a posição da empresa em relação a estar na frente ou não no desenvolvimento de competências.

Compreendida a importância estratégica associada à formação e desenvolvimento de competências, torna-se portanto, necessário o estudo do processo de sua criação e evolução.

\section{0 processo de aprendizagem organizacional}

A aprendizagem organizacional é um processo complexo e dinâmico de geração de conhecimento organizacional que sofre a influência de um grande número de variáveis que mantém entre si relações complexas e freqüentemente subjetivas. A eficiência do aprendizado é evidenciada pela capacidade, considerada essencial, de estabelecer uma relação causal entre ações e resultados, independentemente destes resultados terem provido ou não um desempenho positivo em relação aos demais competidores. Nadler, Gerstein e Shaw (1992) abordam o aprendizado organizacional como a capacidade de uma organização em adquirir conhecimentos com sua experiência e a experiência de outros, e modificar sua forma de funcionar.

Segundo Fleury e Fleury (2004), o processo de aprendizagem organizacional não envolve apenas a elaboração de novos mapas cognitivos que viabilizam a compreensão da dinâmica dos ambientes interno e externo, mas também a definição de novos comportamentos que evidenciam a efetividade do aprendizado.

Para Nonaka e Ryoko (2003), o conhecimento e a capacidade de criar conhecimento são considerados os fatores mais importantes para a sustentabilidade das vantagens competitivas, tornando o entendimento do processo de aprendizagem organizacional um fator relevante. A dificuldade maior está localizada em falhas no entendimento da essência do processo de criação do conhecimento, como a "sintetização" de processos. Os agentes sofrem influência do ambiente e o ambiente sofre recriação contínua, através da interação social; assim, o conhecimento é criado através da interação entre conhecimento tácito e explícito, nos diferentes níveis da organização e do ambiente.

A compreensão das dificuldades que se interpõem à aprendizagem organizacional e do processo de geração do conhecimento pode ser a chave para o desenvolvimento do processo de criação e formação de competências.

\subsection{Barreiras à aprendizagem}

O processo de aprendizagem organizacional caracteriza-se por um amplo, complexo e dinâmico conjunto de relações entre diversas variáveis. Estas características podem ser estudadas a luz das barreiras que formam ao longo desta complexa rede de relações. O estudo das barreiras pode contribuir para a organização e gestão do processo de aprendizagem.

Para Davenport e Prusak (2002), os valores e crenças exercem forte impacto no conhecimento organizacional, porque influenciam a visão, os pensamentos e os atos das pessoas, logo, o poder de organização, seleção, aprendizado e julgamento do conhecimento, provém de valores e crenças, tanto quanto a informação provém da lógica.

Dentre os vários fatores que influenciam o ciclo de aprendizagem organizacional, predominam os que têm origem na cultura organizacional, ou seja, no conjunto de valores e crenças da organização. Tais fatores podem configurar-se como barreiras ao processo de aprendizagem e, conseqüentemente, à formação de competências nas empresas. As barreiras à aprendizagem podem existir em vários estágios do ciclo de aprendizagem, como nos níveis da ação, da reflexão e da disseminação do conhecimento, logo, seu diagnóstico não é um processo simples e pode exigir o envolvimento de todas 
as pessoas da organização (NADLER; GERSTEIN; SHAW, 1992). A Figura 7 apresenta as barreiras, suas causas e efeitos.

\begin{tabular}{|l|l|l|}
\hline Barreira & Causas & Efeitos \\
\hline $\begin{array}{l}\text { Capacidade insuficiente de } \\
\text { refletir e interpretar. }\end{array}$ & $\begin{array}{l}\text { Pressões sobre o desempenho } \\
\text { Incorreta mobilização de competências } \\
\text { Ausência de foros de aprendizado }\end{array}$ & $\begin{array}{l}\text { Negação dos problemas } \\
\text { Análise incompleta } \\
\text { Análise incorreta }\end{array}$ \\
\hline $\begin{array}{l}\text { Capacidade insuficiente de } \\
\text { disseminar o conhecimento }\end{array}$ & $\begin{array}{l}\text { Limites intergrupos } \\
\text { Mito da singularidade } \\
\text { Faixas estreitas de informação }\end{array}$ & $\begin{array}{l}\text { Ignorância dos problemas } \\
\text { Ignorância das soluções } \\
\text { Redundância de esforços }\end{array}$ \\
\hline Capacidade insuficiente de agir & $\begin{array}{l}\text { Tensão sobre prioridades } \\
\text { Inclinação para as atividades em } \\
\text { detrimento dos resultados } \\
\text { Falta de autonomia }\end{array}$ & $\begin{array}{l}\text { Falta de experimentação } \\
\text { Falhas na implementação }\end{array}$ \\
\hline
\end{tabular}

Figura 7 - Barreiras à aprendizagem organizacional. Adaptado de Nadler, Gerstein e Shaw, 1992.

Na barreira que descreve a capacidade insuficiente para refletir e interpretar, observa-se o não estabelecimento de elos de causa-efeito. As prováveis causas desta barreira associam-se a: uma pressão pelo desempenho, onde a reflexão é considerada dispêndio improdutivo de tempo; incorreta mobilização de competências, isto é, em ambientes com pressão pelo desempenho as pessoas tendem a usar os métodos que melhor conhecem, mesmo quando são necessárias novas abordagens; ausência de foros e estruturas de aprendizado, ou seja, espaços com liberdade para tentar, e eventualmente errar. Há o predomínio de práticas padronizadas que fazem parte da cultura organizacional, o comportamento dos indivíduos é orientado por pressupostos básicos, em detrimento do teste das suas convicções individuais. Estas rotinas, mesmo quando não são percebidas, evitam o constrangimento e os conflitos de um eventual erro ocasionado pelo próprio raciocínio (NADLER; GERSTEIN; SHAW, 1992).

A capacidade insuficiente de disseminar conhecimento é outra barreira que se interpõe ao desenvolvimento do processo de aprendizagem organizacional. Nesta barreira não há intercâmbio colaborativo de idéias com perspectivas diferentes e o conhecimento fruto da reflexão não é disseminado pela organização

Nos limites intergrupos, onde, as distinções entre chefes e funcionário formam grupos isolados, podese dizer que há a identificação dos problemas e o desenvolvimento de soluções, mas sua abordagem não é compartilhada por toda a organização. O mito da singularidade descreve que pessoas e grupos acham que são diferentes dos outros, e por atuarem em mercados distintos crêem que as alternativas para resolução de problemas de uma região não possam ser utilizadas em outra região. As faixas estreitas de informação limitam a experimentação e a implementação (NADLER; GERSTEIN; SHAW, 1992).

Na barreira descrita pela capacidade insuficiente de agir, as pessoas identificam problemas, desenvolvem soluções, mas não conseguem colocá-las em prática. Prováveis causas apontam para a tensão sobre prioridades, excesso de prioridades e objetivos confusos. Também contribui para a construção desta barreira a inclinação para as atividades em detrimento dos resultados. A falta de autonomia, outra provável causa, ocorre quando as responsabilidades não são claras e as equipes são controladas demais (NADLER; GERSTEIN; SHAW, 1992).

A eliminação das barreiras à aprendizagem é fator crucial para a efetividade do processo de aprendizagem, ou seja, a criação de conhecimento e a formação e desenvolvimento de competências organizacionais.

\subsection{Geração de Conhecimento}

Nonaka (1991) aborda a criação de conhecimento como uma interação dinâmica, sendo que estas possuem três características básicas: 
- Dificuldade de transformação de informações específicas em conhecimento útil (sinais vagos e ambíguos do mercado);

- Dificuldade em comunicar aos outros, provocando mudança ou perda do significado da informação em diferentes contextos;

- Discrepâncias, que podem ser fonte de novo conhecimento que nem sempre é percebido.

Para Nonaka e Ryoko (2003), a chave para o entendimento do processo de criação do conhecimento é a dialética entre pensar e agir, que transcende e sintetiza as contradições, integrando opostos, como o processo dinâmico de diálogo e prática, onde novos conceitos e estruturas de interação são criados, e a empresa se envolve em um ciclo de criação de conhecimento.

O conhecimento confere a habilidade de reconhecer o valor da nova informação, assimilá-la e aplicála para fins comerciais. Deste modo, a capacitação de absorção do conhecimento constitui uma habilidade que possibilita estabelecer uma relação entre o objeto do aprendizado e o conhecimento existente (COHEN; LEVINTHAL, 1990).

Fleury (2004, p. 43) destaca três momentos no processo de criação ou geração de conhecimento: a aquisição e desenvolvimento de conhecimentos, a disseminação e a construção da memória (FIGURA 8).

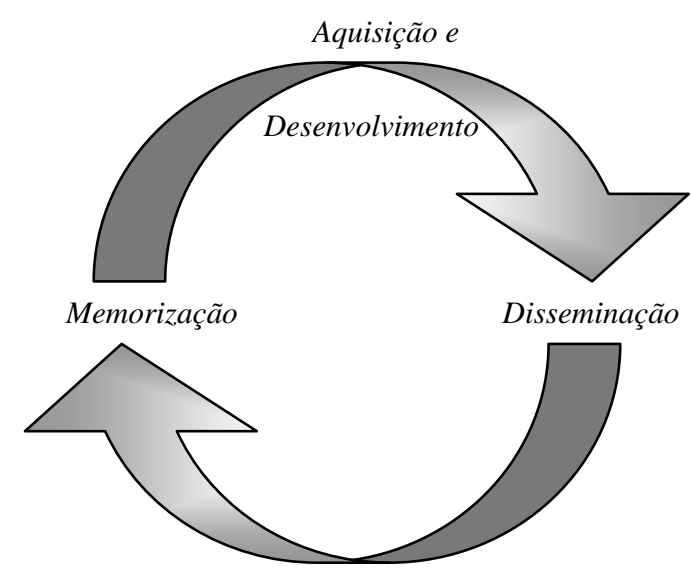

Figura 8 - Aquisição do conhecimento (Fonte: FLEURY, 2004, p. 43)

a. Aquisição de conhecimento e o desenvolvimento de competência:

Podem ocorrer por processos proativos ou reativos. O processo proativo ocorre em antecipação aos demais competidores, incluem-se aqui a experimentação e a inovação, que consistem na geração de novos conhecimentos e metodologias e originam novos produtos e serviços baseados em situações não rotineiras. O processo reativo ocorre como uma reação a uma situação já existente. Os processos reativos envolvem a resolução sistemática de problemas, observação e análise de experiências realizadas por outros, como uma forma de aprendizado e a contratação de pessoas como fonte de renovação do conhecimento na empresa.

b. Disseminação de conhecimento:

Ocorre por intermédio de diversos processos como: a comunicação e circulação de informação de forma rápida e eficiente pela empresa; pelo treinamento, que talvez caracterize a forma mais comum de disseminar conhecimentos e competências; a rotação de pessoas de tal forma que possam vivenciar várias situações de trabalho; e o trabalho em equipes multidisciplinares, com interação de pessoas de diferentes perfis, facilitando a disseminação de idéias, propostas e novas soluções para problemas.

c. Memorização do conhecimento: 
É o processo de armazenagem de informações baseadas na história organizacional, as quais podem ser resgatadas e utilizadas como apoio à tomada de decisões. O estoque de informações deve considerar as experiências bem sucedidas e mal sucedidas. A construção da memória organizacional viabiliza a existência da organização independentemente deste ou daquele indivíduo, pois a informação permanece na empresa mesmo após o desligamento do indivíduo.

Segundo Nonaka (1991), o novo conhecimento sempre se origina no indivíduo, através de um ciclo de conversão de conhecimento tácito em explícito, que caracteriza uma forma de expressar o que está na mente das pessoas, utilizando a articulação de intuições e insights. Também este autor cita que no nível corporativo, para gerar-se conhecimento é necessário que o grupo tenha um claro senso de direção, uma visualização da dinâmica do processo de criação do conhecimento, na qual a organização interage com os indivíduos. Nonaka (ibid.) aponta a linguagem figurativa como a utilização de metáforas no ambiente corporativo, como um método distintivo de percepção, indicando novos caminhos para a identificação do que se sabe e não se pode expressar ainda.

A Figura 9 ilustra o processo de conversão de conhecimento tácito e explícito segundo a abordagem de Nonaka (1991).

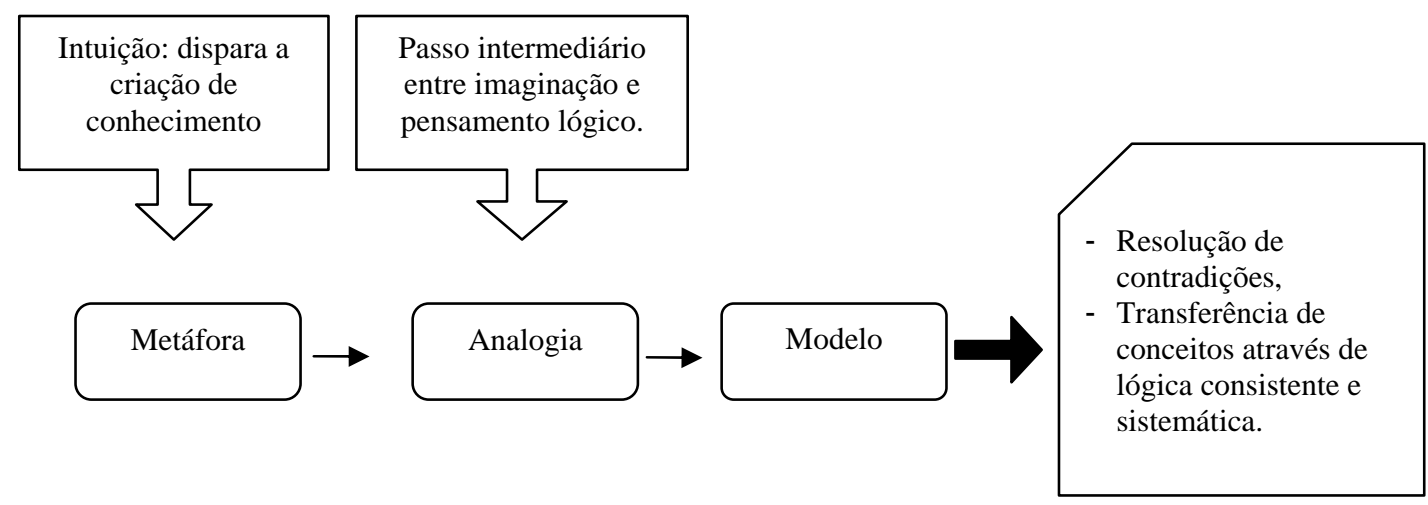

Figura 9 - Linguagem figurativa no processo de aprendizagem. Adaptado de Nonaka, 1991.

A metáfora possibilita uma percepção menos complexa da realidade e facilita a compreensão. A analogia com modelos reais encontra-se em um nível intermediário entre a imaginação e a lógica e possibilita a consolidação do modelo. Este último engloba a resolução das contradições e a transferência de conceitos através de uma lógica consistente e sistemática (NONAKA, 1991).

O desenvolvimento da visão metafórica para a visão do modelo é abordado por Nonaka (1991), como uma evolução do caos para o conceito, expressada no processo de criação de conhecimento durante a transformação de conhecimento tácito em explícito.

O domínio do conhecimento não provém resultados financeiros positivos por si só, mas constitui um recurso de importância crescente com a emergência da sociedade do conhecimento e sua mobilização competente em conjunto com os demais recursos organizacionais é o que possibilita a geração de resultados de desempenho positivos para a empresa.

\subsection{Construção de competências organizacionais}

Com base na construção teórica desenvolvida ao longo do artigo, foi elaborado um modelo que reúne os elementos envolvidos e representa o processo de construção das competências organizacionais. O conhecimento das relações de causa e efeito permite se desenvolver uma solução baseada na memória organizacional e o nível de desempenho reflete o nível de desenvolvimento das competências organizacionais. 
A visualização da efetividade da aprendizagem organizacional constitui um desafio fundamental, e requer uma visão sistemática que engloba o resultado de todo o processo. (NADLER; GERSTEIN; SHAW, 1992).

O ciclo de aprendizagem organizacional (FIGURA 10) sofre influência de uma série de elementos que compõem o sistema de crenças da organização, e tem a sua efetividade condicionada à eficácia nos níveis da reflexão, disseminação e ação. Tais elementos representam:

- Sistemas de crenças: constituído pelos valores da organização, pela base de conhecimento e pelo know how de experiências anteriores;

- Conhecimento organizacional: caracteriza um recurso estratégico da empresa, quando é aplicável para inovação de produtos, serviços e processos;

- Competências organizacionais: definem a mobilização dos recursos, por meio de processos e atividades que definem a estratégia de operações.

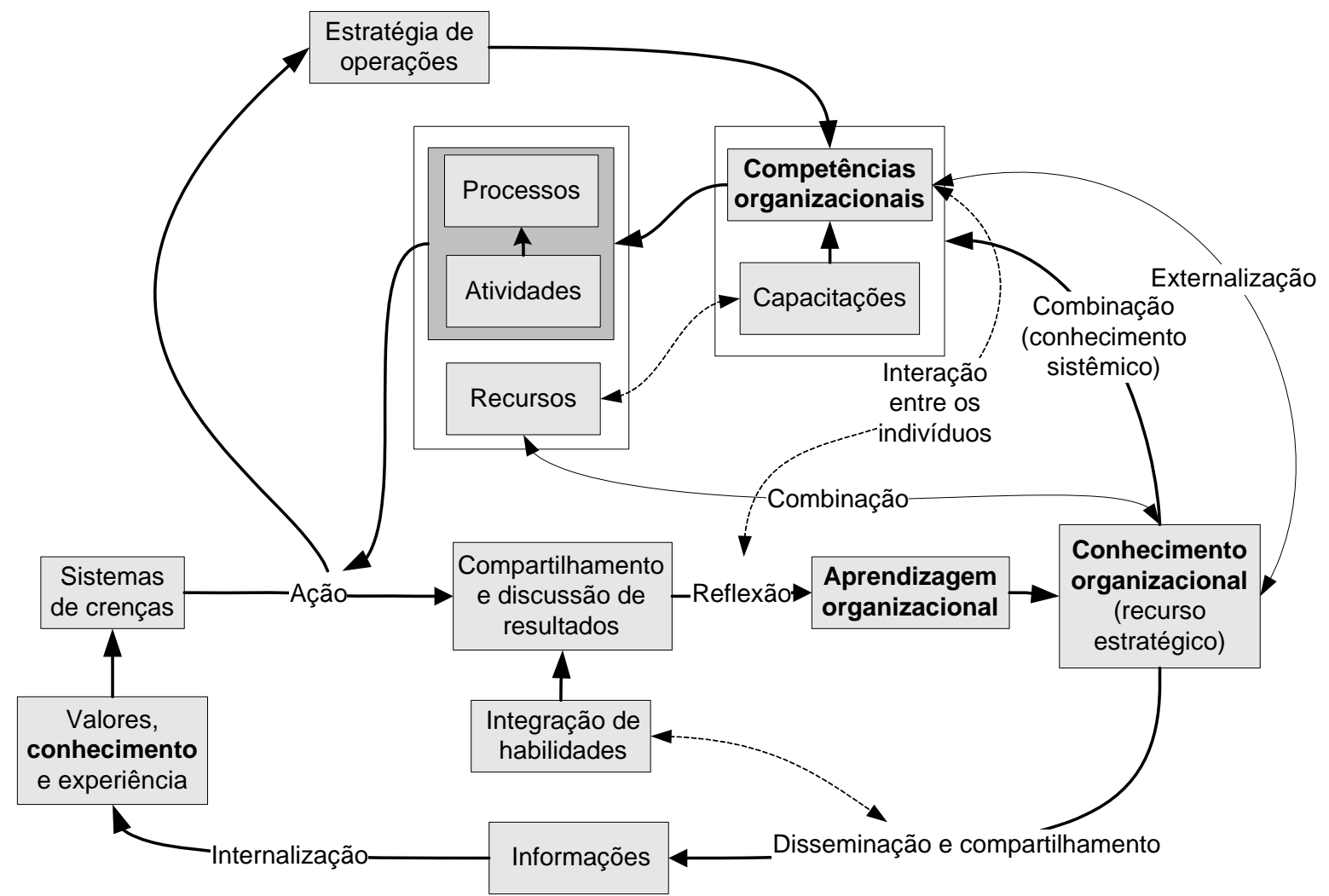

Figura 10 - Processo de aprendizagem organizacional. Elaborado pelos autores.

Murray (2003) aborda a formação de competências organizacionais como o resultado do trabalho conjunto dos recursos da empresa. A mobilização dos recursos para a construção de competências implica em um processo complexo de coordenação entre as pessoas e entre pessoas e recursos, que conduz a sustentabilidade das vantagens competitivas no longo prazo. As ações estratégicas refletem as potencialidades da organização em formar competências superiores, emergentes do processo de aprendizagem.

As discussões acerca da aprendizagem nas organizações estão mais fortemente ligadas à perspectiva cognitivista, que envolve a aprendizagem de conceitos e a resolução de problemas, e que utiliza tanto dados objetivos e comportamentais como também dados subjetivos, que consideram as crenças e percepções individuais. A análise sob esta perspectiva enfatiza como as pessoas desenvolvem as competências necessárias à organização e ao seu projeto profissional (FLEURY; FLEURY, 2004). A definição da estratégia competitiva permite a empresa identificar as competências essenciais do negócio e as competências necessárias a cada função; competências estas que, por sua vez, 
possibilitam as escolhas estratégicas da organização. Deste modo é viabilizada a conjugação de situações de aprendizagem que podem propiciar a transformação de conhecimento em competências que agregam valor ao indivíduo e à organização. Fleury e Fleury (2004) ponderam que competitividade de uma organização pode ser determinada pela inter-relação dinâmica entre competências organizacionais e estratégia competitiva. As situações que refletem a efetividade da aprendizagem organizacional podem ser verificadas na interpretação dos resultados:

- Sucesso produtivo: quando a empresa obtém resultados de desempenho positivos e estabelece vínculos entre as ações que possibilitaram tais resultados;

- Fracasso produtivo: mesmo obtendo resultados de desempenho negativos, a fase de reflexão estabelece relações causais entre ações e resultados, e aprende com a experiência como evitar o mesmo erro futuramente;

- Sucesso improdutivo: a empresa volta-se para o resultado de desempenho positivo, e não investiga ou estabelece vínculos de como e porque tais resultados foram possíveis;

- Fracasso improdutivo: a organização obtém resultados negativos com a implementação das ações, e descarta tais ações sem investigar ou identificar os elos de causa e efeito, cuja interpretação poderia ser uma fonte importante de conhecimento para aprender e evitar os mesmos erros no futuro.

Desenvolvido o processo de aprendizagem organizacional e estabelecidas as relações com a criação de conhecimento e a formação e desenvolvimento de competências, pode-se estudar as suas relações com o projeto organizacional.

\section{0 processo de aprendizagem e o projeto organizacional}

O projeto organizacional de um empreendimento no ambiente de incertezas e complexidade, com objetivos de desempenho associados à flexibilidade e inovação, implica no surgimento de uma nova forma de organização da produção e do trabalho, e traz intrínsecas características como a democratização das relações de trabalho, flexibilização de operações, maior grau de inovação de produtos e processos, novos critérios de desempenho e aprendizagem técnica e organizacional (SALERNO, 1999).

Um bom projeto organizacional é um fator chave para a melhoria no desempenho na criação de produtos e serviços. Existe um esforço no sentido de definir o papel das relações entre estratégia, mercados, produtos, processos e tecnologia; e de evidenciar o papel do projeto organizacional como um dos determinantes da efetividade operacional (RUFFINI; BOER; RIEMSDIJK, 2000).

Para que ocorra a aprendizagem, é necessário que o projeto organizacional apresente as condições favoráveis, iniciativas de compartilhamento e disseminação do conhecimento crítico para a organização, envolvendo elementos como:

- Comprometimento de todos os níveis hierárquicos da organização sobre a importância do processo de aprendizagem para a geração de capacitações e competências organizacionais no âmbito da gestão de operações;

- Identificação do conhecimento crítico ou estratégico para a organização que possa originar competências;

- Conscientização e/ou capacitação dos detentores do conhecimento crítico, de modo que ele seja adequadamente explicitado;

- Disseminação do conhecimento organizacional explicitado;

- Comprometimento dos indivíduos e grupos com a internalização do conhecimento explícito crítico;

- Construção de redes de aprendizado entre os indivíduos e grupos, onde possam ser compartilhadas idéias e experiências. 
O modelo da competência prioriza equipes auto gerenciadas, com rotatividade dos operários em todas as funções, intensivas em coordenação e comunicação como forma de resolução de problemas. Este modelo tem como principais características a diminuição da importância do posto de trabalho frente às equipes coletivamente responsáveis, o abandono dos princípios tayloristas e a importância crescente na direção da competência das pessoas, em lugar da qualificação específica para o cargo (ZARIFIAN, 1995).

O desenvolvimento de competências no contexto organizacional requer comunicação eficiente na rede de conhecimento onde se inserem os indivíduos, uma vez que engloba as relações entre as pessoas que compõem a organização. A competência empresarial é o conjunto de qualidades e características que a empresa desenvolve e aperfeiçoa continuamente e competência gerencial é o conjunto de qualidades e características que os gerentes desenvolvem para atingir continuamente os resultados da empresa. A abrangência da competência é global, na medida em que é um pré-requisito para o sucesso da organização inserida em um ambiente complexo e mutável, e abrange todas as áreas da empresa como os processos de produção, comercialização e de apoio, como finanças, recursos humanos, e outros (BOOG, 1991).

A definição dos processos em um sistema organizacional tem duas dimensões: uma que se refere à gestão por processos e outra de natureza estrutural ou organizacional (LIMA, P.; COSTA, G, 2004). O projeto organizacional envolve a sistematização de processos em função do crescimento da organização e da necessidade de obter ganhos em competitividade.

A verificação da realização dos objetivos requer a mensuração do desempenho das ações realizadas através dos fatores de desempenho. Desta forma, estabelece-se uma relação entre os processos e as competências, que tem uma conotação estratégica além da perspectiva natural "recurso-capacitação”, ou seja, por um lado estabelecem os objetivos e por outro estruturam e sustentam a ação organizacional. (LIMA, P.; COSTA, G, 2004). Os processos de aprendizagem em todos os níveis organizacionais são críticos para gerar o conhecimento e flexibilizar as operações.

Para Salerno (1999), o projeto de sistemas organizacionais não deve levar em conta somente a estática, mas também a dinâmica, definida pelos ajustes na estratégia de produção e pelas necessidades trazidas pelos eventos reais do cotidiano. A aprendizagem organizacional remete a esta dinâmica, onde novos conhecimentos são criados continuamente, podendo influenciar o projeto organizacional, priorizando resultados e não tarefas.

Salerno (1999, p. 23) destaca oito aspectos dos sistemas organizacionais inovadores:

1. Organização e gestão por processos (transversais), em contraposição àquela funcional/departamentalizada;

2. Coordenação das atividades de trabalho direto feita prioritariamente no nível operário e não pela supervisão direta (hierarquia) ou pelo dispositivo técnico;

3. Trabalho em grupo com autonomia, onde a definição do método e da divisão do trabalho seja prerrogativa do grupo, e não uma função externa, em contraposição ao conceito clássico de tarefa;

4. Polivalência como uma multiqualificação - qual seja o desenvolvimento de um repertório profissional mais geral e variado, envolvendo um aumento da competência para lidar com os eventos do mundo fabril - e não como uma multitarefa;

5. Um novo olhar para a comunicação intersubjetiva no trabalho e a inserção do operário direto em atividades classicamente consideradas como de apoio ou gestão, alargando seu raio de ação, de poder e de nível de decisão na empresa, o que significa uma ruptura com a rígida divisão de áreas de atuação (produção-gestão, produção-projeto);

6. Uma mudança na política de recursos humanos, coerente com a perda da importância relativa da noção de posto de trabalho, de cargos associados aos postos e de tarefas predefinidas relativas a postos e a cargos dados; 
7. A procura de um novo sistema de gestão econômica da produção e da empresa que supere os problemas colocados pela contabilidade gerencial e analítica e pela modelagem corrente, integrando gestão física da produção (volumes, prazos, qualidade, etc.) e gestão econômico-financeira;

8. Sistemas tecnológicos avançados, caracterizados por um nível elevado de integração e flexibilidade, baseados em automação microeletrônica e redes de computadores.

O conhecimento só pode ser criado pelas pessoas. Assim, para o projeto de organizações do conhecimento, deve-se considerar a dimensão humana, ou seja, o conhecimento não pode ser extraído de informações armazenadas em uma base de dados (LAISE; MIGLIARESE; VERTERAMO, 2005). A interação entre as pessoas atuantes na organização, o compartilhamento de experiências e informações e a disseminação de conhecimento, são fatores críticos a serem considerados no projeto organizacional inovador, e estes comportamentos requerem maior grau de autonomia dos indivíduos.

Dos conceitos e modelos apresentados, verifica-se que o lugar de interação entre conhecimento organizacional, competências organizacionais e aprendizagem organizacional é representado pelos diferentes processos organizacionais e de gestão, na medida em que mobilizam a base de conhecimento organizacional através das competências organizacionais; e também se faz a gestão do desempenho que pode ser resultado da aprendizagem organizacional. Também é clara a necessidade de se desenvolver espaços organizacionais para a socialização e disseminação do conhecimento, o que a caracterizaria um espaço para aprendizagem e gestão participativa. As estruturas organizacionais, na medida da definição dos mecanismos de coordenação vertical e lateral, nos níveis da organização das unidades ou do trabalho, devem permitir a colaboração e o desenvolvimento da autonomia.

\section{Conclusão}

A aprendizagem organizacional não é refletida apenas em resultados de desempenho positivos no curto prazo, mas principalmente na interpretação e entendimento profundo dos processos de ação, reflexão e disseminação. Toda ação da empresa implicará em resultados, que são analisados, interpretados e ligados às ações prévias. É no nível da reflexão que são estabelecidos elos de causa e efeito que podem determinar se o sucesso ou fracasso foram produtivos ou improdutivos para a empresa, do ponto de vista da geração de conhecimento.

A rapidez no aprendizado organizacional é uma vantagem competitiva importante em um ambiente dinâmico e de alta competitividade como a economia do conhecimento, logo, a eliminação das barreiras à aprendizagem é um fator chave para possibilitar o incremento da base de conhecimento das organizações.

Por outro lado, é primordial e necessária a avaliação ampla da situação da empresa, o planejamento, a implementação e o monitoramento de mudanças que proporcionem condições para o aprendizado. A identificação de conhecimentos e competências que a empresa necessita desenvolver e a eliminação das barreiras à aprendizagem são fundamentais para evitar o dispêndio de recursos, pois a principal competência organizacional deve ser a habilidade para mudar e adicionar valor aos produtos e serviços.

A real contribuição do processo de aprendizagem organizacional não está apenas no provimento de resultados de desempenho com ganhos de competitividade ou resultados financeiros positivos, mas na interpretação dos resultados, que pode fornecer informações úteis para a geração de conhecimento e competências mesmo em situações onde o resultado de desempenho foi negativo.

O processo de aprendizagem só conseguirá obter os reais benefícios associados à criação de conhecimento e formação de competências organizacionais, se estiver associado a um adequado projeto organizacional. Tal adequação pode ser medida nas dimensões associadas aos processos organizacionais, aos espaços organizacionais e às estruturas organizacionais. 


\section{Referências}

ARGYRIS, C.; SCHÖN, D. A. Organizational learning II: theory, method and practice. Reading: Addison-Wesley, 1996.

BARNEY, J. Firm resources and sustained competitive advantage. Journal of Management. v. 17, n. 1, p. 99-120, 1991.

BOLWIJN, P. T.; KUMPE, T. Manufacturing in the 1990s - Productivity, flexibility and Innovation. Long Rang Planning. v. 23, n. 4, p. 44-57, 1990.

BOOG, G. G. O desafio da competência: como enfrentar as dificuldades do presente e preparar sua empresa para o futuro. São Paulo: Best Seller, 1991.

CHAKRAVARTHY, Bala. A new strategy framework for coping with turbulence. Sloan Management Review, v. 38, n. 2, p. 69-82, winter 1997.

CHIEZA, V.; MANZINI, R. Competence levels within firms: a static and dynamic analysis. In: SANCHEZ, R.; HEENE, A. (eds.). Competence-based strategic management. Chichester : Jonh Wiley and Sons, 1997, p. 195-213.

COHEN, W. M.; LEVINTHAL, D. A. Absorptive capacity: a new perspective on learning and innovation. Administrative Science Quaterly, v. 35, p. 128-152, 1990.

DAVENPORT, T. H.; PRUSAK, L. Conhecimento empresarial: como as organizações gerenciam o seu capital intelectual. 6. ed. Rio de Janeiro: Campus, 2002.

EASTERBY-SMITH, M.; BURGOYNE, J.; ARAUJO, L. Aprendizagem organizacional e organização de aprendizagem: desenvolvimento na teoria e na prática. São Paulo: Atlas, 2001.

FERNANDES, A. C. Conhecimento e Aprendizagem Organizacional em Perspectiva. In: SEMINÁRIO BUSINESS IN THE KNOWLEDGE ERA: NOVOS MODELOS DE NEGÓCIOS NA SOCIEDADE DO CONHECIMENTO, 1., 1998, Rio de Janeiro. Anais... Rio de Janeiro: COMPETENET, 1998. Disponível em: <http://www.competenet.org.br/evento/amarildo.pdf>. Acesso em: 15/05/2005.

FERNANDES, B. H. R. Competências e performance organizacional: um estudo empírico. São Paulo, 2004. 232f Tese (Doutorado em Administração de Empresas) - Universidade de São Paulo.

FLEURY, M.T.L.; FLEURY, A.C.C. Alinhando estratégia e competências. Revista de Administração de Empresas, v. 44, n. 1, p. 44-69, 2004.

FLEURY, A. C. C.; FLEURY, M. T. L. Estratégias competitivas e competências essenciais: perspectivas para a internacionalização da indústria no Brasil. Gestão e Produção, v. 10, n. 2, p.129144, 2003.

FLEURY, A. C. C.; FLEURY, M. T. L. Estratégias empresariais e formação de competências: um quebra-cabeça caleidoscópico da indústria brasileira. 3. ed., São Paulo: Atlas, 2004.

FLEURY, M. T. L.; FLEURY, A. C. C. Construindo o conceito de competência. Revista de Administração Contemporânea, v. 5, p. 183-196, 2001.

FLYNN, B. B.; FLYNN, E. J. An exploratory study of the nature of cumulative capabilities. Journal of Operations Management, v. 22, n. 5, p. 439-457, 2004. 
GARVIN, D. A. The processes of organization and management. Sloan Management Review, v. 39, n. 4, p. 33-50, 1998.

HAMEL, G.; PRAHALAD, C. K. Competindo pelo Futuro: estratégias inovadoras para obter o controle do seu setor e criar os mercados de manhã. Rio de Janeiro: Campus, 1995.

KUPFER, David. Padrão de concorrência e competitividade. Texto para discussão IEI/UFRJ. Rio de Janeiro, n. 265, 1991.

LAISE, D.; MIGLIARESE, P.; VERTERAMO, S. Knowledge organization design: a diagnostic tool. Human Systems Management, v. 24, p. 121-131, 2005.

MILLS, J.; PLATTS, K.; BOURNE, M.; RICHARDS, H. Strategy and performance: competing through competences. Cambridge: Cambridge University Press, 2002.

MURRAY, P. Organizational learning, competencies, and firm performance: empirical observations. The Learning Organization. v. 10, n. 5, p. 305-316, 2003.

NADLER, D.; GERSTEIN, M. S.; SHAW, R. B. Arquitetura organizacional: a chave para a mudança empresarial. Rio de Janeiro: Campus, 1992.

NONAKA, I. The Knowledge-Creating Company. Harvard Business Review, v. 69, p. 96-104, 1991.

NONAKA, I; RYOKO, T. The knowledge-creating theory revisited: knowledge creation as a synthesizing process. Knowledge Management Research \& Practice, n. 1, p.2-10, 2003.

PENROSE, E. T. The theory of the growth of the firm. Oxford: Basil Blackwell, 1959.

PEREIRA, S. L.; PINHEIRO DE LIMA, E.; RODRIGUES, L. S. The knowledge structures analyzed by the organizational dimensions. In: PORTLAND INTERNATIONAL CONFERENCE ON MANAGEMENT OF ENGINEERING AND TECHNOLOGY - PICMET'99, 3., 1999, Portland. Proceedings... Portland: PICMET, 1999.

PINHEIRO DE LIMA, E.; GOUVÊA DA COSTA, S. E. Uma metodologia para a condução do processo associado ao projeto organizacional de sistemas de operações integradas. Revista Produção, v. 14 n. 2, p. 24-41, 2004.

PORTER, M. E. Estratégia competitiva: técnicas para análise de indústrias e da concorrência. Rio de Janeiro: Campus, 1986.

PORTER, M. E. Vantagem competitiva: criando e sustentando um desempenho superior. Rio de Janeiro: Campus, 1989.

PRAHALAD, C. K.; HAMEL, G. The core competence of the corporation. Harvard Business Review, p. 3-15, 1990.

RUFFINI, F. A. J.; BOER, H.; RIEMSDIJK, M. J. Organisation design in operations management. International Journal of Operations \& Production Management, v. 20, n. 7, p. 860-879, 2000.

SALERNO, Mario Sergio. Projeto de organizações integradas e flexíveis: processos, grupos e gestão democrática via espaços de comunicação-negociação. São Paulo: Atlas, 1999.

SANCHEZ, R. Managing articulated knowledge in competence-based competition In: SANCHEZ, Ron (ed.); HEENE, Aimé (ed.). Strategic learning and knowledge management. Chichester: John Wiley \& Sons, 1997. p. 163-187. 
SANCHEZ, R.; HEENE, A. A Competence perspective on strategic learning and knowledge management. In: \& Sons, 1997b. p. 3-15. (eds). Strategic learning and knowledge management. Chichester: John Wiley

SANCHEZ, R.; HEENE, A. Competence-based strategic management: concepts and issues for theory, research, and practice. In: Wiley and Sons, 1997a. p. 3-42. (eds.). Competence-based strategic management. Chichester : Jonh

SANCHEZ, R.; HEENE, A.; THOMAS, H. Towards the theory and practice of the competence-based competition. In: (eds). Dynamics of competence-based competition: theory and practice in the new strategic management. Oxford: Elsevier, 1996.

SAVAGE, C. M. 5th Generation management: co-creating through virtual enterprising, dynamic teaming, and knowledge networking. Boston: Butterworth-Heinemann, 1996.

SELLEN, W. Knowledge management in resource-based competitive environments: a roadmap for building learning organizations. Journal of Knowledge Management, v. 4, n. 4, p. 346-356, 2000.

SENGE, P. M. A quinta disciplina: arte e prática da organização de aprendizagem. 7. ed., São Paulo: Best Seller, 2000.

STALK, G.; EVANS P.; SHULMAN, L.E. Competing on capabilities: the new rules of corporate strategy. Harvard Business Review, p. 57-69, march-april 1992.

TEECE, D.; PISANO, G. The Dynamic capabilities of firms: an introduction. Industrial and Corporate Change, v. 3, n. 3, p. 537-556, 1994.

TEECE, D.; PISANO, G.; SHUEN, A. Dynamic capabilities and strategic management. Strategic Management Journal. v. 18, n.7, p. 509-533, 1997.

VOLBERDA, H. W. Building flexible organizations for fast-moving markets. Long Range Planing, v. 30, n. 2, p. 169-183, 1997.

WERNERFELT, B. A resource-based view of the firm. Strategic Management Journal. v. 5, n. 2, p. 171-180, 1984.

WERNERFELT, B. The resource-based view of the firm: ten years after. Strategic Management Journal. v. 16, n. 3, p. 171-174, 1995.

WHITEHILL, M. Knowledge-based strategy to deliver sustained competitive advantage. Long Range Planning, v. 30, n. 4, p. 621-627, 1997.

ZARIFIAN, P. Novas formas de organização e modelo da competência na indústria francesa. In: Workshop Implementação de Novas Formas de Organização do Trabalho, 1., 1995, São Paulo. Anais...São Paulo, 1995. p.1-17.

ZARIFIAN, Philippe. Objetivo competência: por uma nova lógica. São Paulo: Atlas, 2001. 